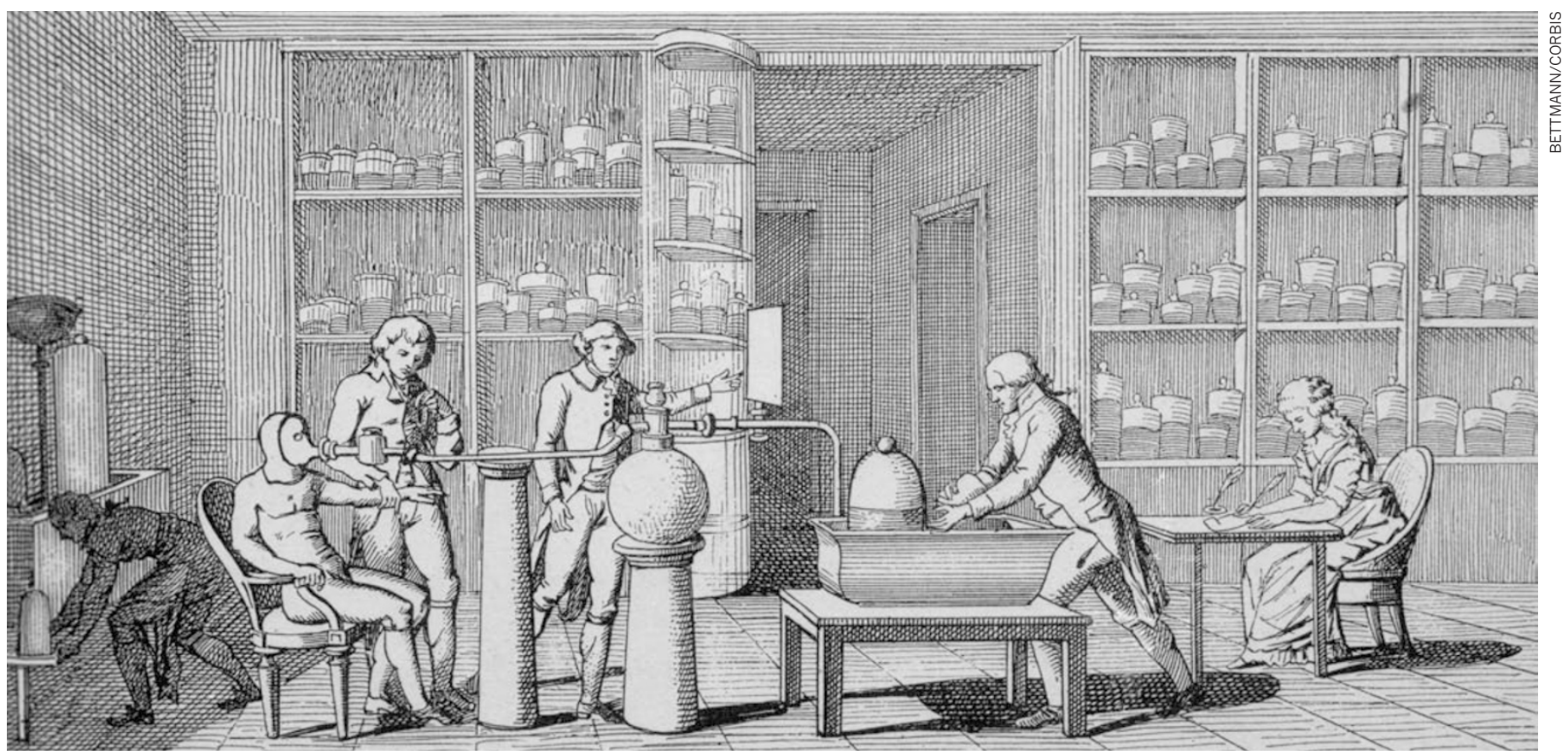

Eighteenth century chemist Antoine Lavoisier investigates whether exhaled breath is analogous to the fumes of a combustion engine.

\title{
HISTORY
}

\section{The changing notion of food}

\section{The pioneers of nutrition research determined the energy content of food and also helped to overturn misconceptions about various diseases that plagued humankind.}

\section{BY NED STAFFORD}

$\mathrm{N}$ utrigenomics - and the rest of modern nutrition science - stands on foundations laid in the late eighteenth century.

That is not to say that nobody had taken an interest before then in how food works. The ancient civilizations of Egypt, Greece, Rome, Persia, China and India were aware of a link between food and health. "They all had their food rules, many of which are still valid today," says Claus Leitzmann, a human nutritionist at the University of Giessen in Germany. "The ancient Egyptians used garlic medicinally."

Some of our food-truths hark back millennia. The ancient Greek physician Hippocrates recommended that food should be thoroughly chewed before swallowing, and consumed in moderation to maintain good health. In the Middle Ages, the German nun and Christian mystic Hildegard of Bingen "knew a lot about food", says Leitzmann. "She made some very intelligent recommendations," such as eating cooked rather than raw foods.

But before the eighteenth century there was little scientific investigation into the composition of food or how the body processes it. The researchers of the time were "dependent on experimental observation", says Leitzmann. Their method was 'feed and watch'. It was French chemist Antoine Lavoisier, regarded as the father of modern chemistry, who first conducted the research that led to today's science of nutrigenomics.

\section{FOOD AS FUEL}

Lavoisier was one of the first scientists to design laboratory equipment to test what happens to food after it is swallowed. Before his work, scientists knew that the weight of ingested food exceeded the weight of excreted faeces and urine. They attributed this loss to perspiration. But Lavoisier believed that food was fuel and that the body, like the fuel-burning engines being developed at the time, must expel carbon dioxide as a product of combustion. He suspected that exhaled carbon dioxide accounted for this lost matter.

To test his theory, in the early 1780s Lavoisier invented a new type of device - the ice calorimeter. It was composed of an outer shell packed with ice, to maintain a constant temperature of $0{ }^{\circ} \mathrm{C}$, encasing a chamber housing a guinea pig. The animal's body heat melted the ice. By weighing water flowing out of the calorimeter, Lavoisier was able to estimate metabolic heat and compare it with the heat produced by a lit candle or burning charcoal.

His theory proved correct. Lavoisier declared: "respiratory gas exchange is a combustion like that of a candle burning."

In today's calorie-counting world, this does not sound like much of a revelation. But at the time it was a breakthrough. "It was theoretically important to realize that the body needed energy to function and that one major function of food is to supply it," says Elizabeth Neswald, a science historian at Brock University in Ontario, Canada. "It was a basis for determining what someone needs to survive; what leads to weight gain, what leads to weight loss, what enables physical labour and what the relationship between food and physical labour is."

Lavoisier's research also emphasized the importance of food composition and of realizing that faeces, urine, perspiration and respi-
"Early nutrition scientists spent a large part of their time inspecting other people's excrement." ration are an essential part of the equation.

"These early nutrition scientists spent a large part of their time - or their assistants' time - inspecting and analysing other 
people's excrement," says Neswald. "In nutrition experiments, it was vital to assess the differences between input and output - food going in and all products coming out."

This method, known as 'balance trials', was pioneered in the 1830s by French chemist JeanBaptiste Boussingault. He conducted balance trials for nitrogen - a constituent element of proteins - by comparing the nitrogen content of hay, oats and potatoes fed to cows and horses with the animals' excrement and, in the case of cows, milk. He showed that animal feed contained sufficient nitrogen to meet bodily requirements, ending speculation that additional nitrogen was obtained from the atmosphere.

\section{MACRONUTRIENT EXPLORATION}

By the mid-nineteenth century, scientists had learned that the primary elements in food are carbon, nitrogen, hydrogen and oxygen, and had divided food constituents into four main types: carbohydrates, fats, protein and water. Yet the chemical make-up of the first three classes was unknown.

It was a German chemist, Justus von Liebig, who made the next leap forward. The precocious von Liebig (appointed professor at the University of Giessen at age 21) invented the 'kaliapparat', a special piece of glassware for analysis of carbon in organic compounds.

Von Liebig's laboratory, arguably the first teaching laboratory, attracted scientists from around the world. He helped train a generation of nutritional researchers whose work would carry on into the early twentieth century. In the 1860s, for example, two of von Liebig's protégés - physiologist Carl von Voit and chemist Max Joseph von Pettenkofer - obtained funding from the Bavarian government to build a state-of-the-art respiration chamber large enough to hold a person. The chamber could measure the daily balances of both carbon and nitrogen and thereby estimate human protein requirements.

Neswald notes that most of the nutrition research of this period focused not on the health of individuals, but rather on finding the cheapest, easiest methods to feed "institutionalized and impoverished populations" to prevent food riots. Von Voit, says Neswald, visited prisons and workhouses "to assess what people were fed and what their state of health was, with the aim of providing dietary guidelines".

The concept of food as fuel, which contains important dietary components, was further refined in the United States. Agricultural chemist Wilbur Olin Atwater had spent time in von Voit's laboratory as a postdoc, returning to the United States in 1871 to spearhead nutrition science. Atwater spent five years in the 1890 s building a respiration calorimeter

larger than von Voit's and able to hold humans for longer than a day. His measurements were so precise that his energy equivalents for protein, fat and carbohydrate are still used today. Atwater was first to adopt the word 'calorie' as an energy unit for food. (A calorie of food energy is actually equivalent to 1000 calories of thermal energy.)

\section{SMALLER AND SMALLER}

Scientists soon began to realize that in addition to supplying energy and macronutrients, food also played a more subtle role in health and disease. Japanese physician Takaki Kanehiro, who studied in the 1870 s at St Thomas's Hospital Medical School in London, was a rare exception to the nineteenth century German dominance of nutrition. "He was the first person to show that beriberi arises from malnutrition," says Katsuhiko Yokoi, a human nutritionist at Seitoku University in Japan. Previously beri-beri was thought to be an infectious disease.

By the early twentieth century, other scientists around the world had begun to explore links between nutritional deficiencies and other ailments, including rickets and

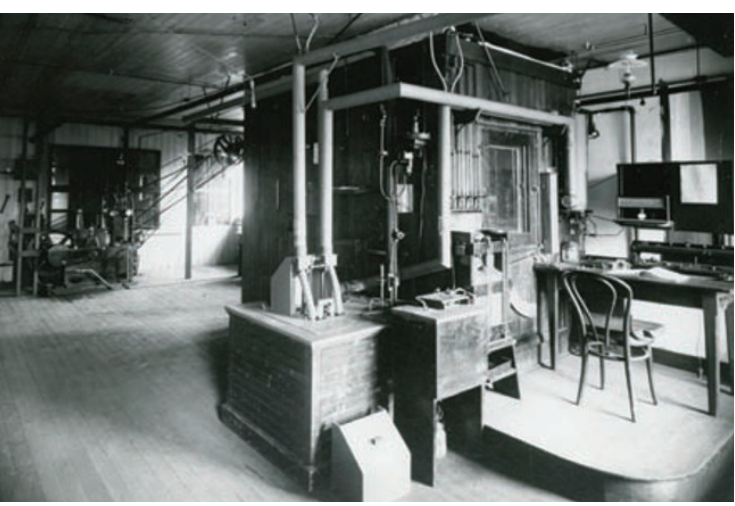

Atwater-Rosa calorimeter used to measure human energy demands.

scurvy. Unable to explain these afflictions in terms of fats, protein or carbohydrates, some scientists began to suspect the existence of another class of food ingredients.

It was Polish biochemist Casimir Funk who in 1912, while studying beriberi, isolated thiamine, the nutrient that protects against this disease. He called the substance a 'vital amine', which soon became 'vitamin'.

The battle against scurvy is an example of science later refining a nutrition-related disease association. In the mid-eighteenth century, Scottish naval physician James Lind found that scurvy could be treated or prevented by eating citrus fruits. But he incorrectly thought that sea air was to blame for the disease. Other erroneous suggestions followed: in 1846, for example, Scottish toxicologist Robert Christison hypothesized that scurvy was caused by protein deficiency. Scurvy continued to be a sporadic problem into the early twentieth century. It was not until 1932 that
US biochemist Charles Glen King showed that scurvy was caused by a deficiency of the newly discovered vitamin C.

Animal research led to further vitamin and disease-related discoveries. US biochemist Elmer Verner McCollum learned German so he could read the works of past nutrition researchers, which inspired him to experiment on rats. At the University of Wisconsin, where McCollum initially worked, research protocols stipulated the use of cows as animal models. But McCollum convinced his superiors to let him try smaller animals. He bought 12 albino rats from a pet store and established the first colony of rats for nutritional experimentation in the United States. In 1913, his studies with these rats led him to identify the first fat-soluble vitamin, vitamin $\mathrm{A}$, and later showed that it is vitamin D - and not vitamin A as some thought - that prevents rickets.

Proving the link between micronutrients and disease didn't come easily. US Public Health Service worker and epidemiologist Joseph Goldberger theorized that pellagra, then a major disease causing diarrhoea, dermatitis, dementia and death, was diet-related and not, as prevailing medical opinion held at the time, an infectious disease. In 1916, to prove his point, Goldberger and his assistant subjected themselves to a series of tests - they injected each other with blood from a pellagra sufferer, swabbed out the secretions of an pellagra-infected person's nose and throat and rubbed them into their own, and swallowed capsules containing scabs of pellagra sufferers' rashes. And yet despite such gross exposure, they did not develop pellagra. However, Goldberger was unable to find the diet-related cause. It was another two decades before American biochemist Conrad Elvehjem realized that pellagra was caused by a deficiency of niacin (vitamin B3).

So many micronutrients had been discovered by 1944 that some believed the field of nutrition had been fully defined with little else to discover. But while the constituent parts of food might have been teased out, their impact on the body was only starting to be appreciated.

From Lavoisier, through von Liebig, to scientists today such as Jose Ordovas (see Big science at the table, page S2), nutrition research has focused on smaller and smaller elements. As scientists have probed deeper into biochemical mechanisms of bodily absorption and function - unlocking mysteries as they go - they have also triggered new questions, until we get to 'how do our genes interact with the food we eat?' And that's the question we are still trying to answer today.

Ned Stafford is a science writer in Hamburg 